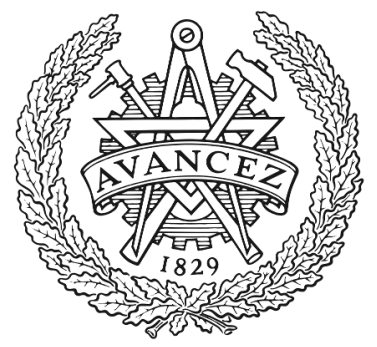

CHALMERS

UNIVERSITY OF TECHNOLOGY

\title{
Service Design in HCI Research: The Extended Value Co-creation Model
}

Downloaded from: https://research.chalmers.se, 2023-04-26 10:59 UTC

Citation for the original published paper (version of record):

Yoo, D., Ernest, A., Serholt, S. et al (2019). Service Design in HCI Research: The Extended Value Co-creation Model. ACM International Conference Proceeding Series.

http://dx.doi.org/10.1145/3363384.3363401

N.B. When citing this work, cite the original published paper. 


\section{Service Design in HCI Research: The Extended Value Co-creation Model}

\author{
Daisy Yoo \\ Aarhus University \\ Aarhus, Denmark \\ dyoo@cc.au.dk
}

\author{
Anya Ernest \\ Chalmers University of Technology \\ Gothenburg, Sweden \\ anya@beingernest.se
}

\author{
Sofia Serholt \\ University of Gothenburg and \\ Chalmers University of Technology \\ Gothenburg, Sweden \\ sofia.serholt@ait.gu.se
}

\author{
Eva Eriksson \\ Aarhus University and \\ Chalmers University of Technology \\ evae@cc.au.dk
}

\author{
Peter Dalsgaard \\ AIAS and Aarhus University \\ Aarhus, Denmark \\ peterd@cc.au.dk
}

\begin{abstract}
In this paper, we discuss what it means to practice service design in an academic research setting. For a long time, the primary focal point of design research has been the users-of their experiences, needs, desires, and values. By contrast, designers have been relatively anonymous and unlocatable. In shift to the service-centric design paradigm, we argue that it is important to recognize design researchers as distinct stakeholders, who actively interact with systems and services with a goal to fulfill their own values and achieve desired outcomes. In practice, typically the role of designer is that of a design consultant working for (or rather on behalf of) the client. By contrast, in academic research settings, the role of designer is that of a design researcher working with their own research agenda.

We provide a case study of a service design research project aimed at developing new digital services for public libraries. We encountered a series of issues with a complex set of values at play, in which design researchers emerged as distinct stakeholders with specific sets of research questions, goals, and visions. The main contribution of this paper is a model that (a) clarifies the position of design researchers within the sociocultural context in which they practice design, and (b) visualize how their positions impact the value co-creation, and in turn, the design outcome.
\end{abstract}

\section{CCS CONCEPTS}

- Human-centered computing $\rightarrow$ Human computer interaction (HCI).

\section{KEYWORDS}

Service design, Interaction design, HCI research, Values

\footnotetext{
Permission to make digital or hard copies of all or part of this work for personal or classroom use is granted without fee provided that copies are not made or distributed for profit or commercial advantage and that copies bear this notice and the full citation on the first page. Copyrights for components of this work owned by others than the author(s) must be honored. Abstracting with credit is permitted. To copy otherwise, or republish, to post on servers or to redistribute to lists, requires prior specific permission and/or a fee. Request permissions from permissions@acm.org. HTTF 2019, November 19-20, 2019, Nottingham, United Kingdom (c) 2019 Copyright held by the owner/author(s). Publication rights licensed to ACM. ACM ISBN 978-1-4503-7203-9/19/11 ..\$15.00

https://doi.org/10.1145/3363384.3363401
}

\section{ACM Reference Format:}

Daisy Yoo, Anya Ernest, Sofia Serholt, Eva Eriksson, and Peter Dalsgaard. 2019. Service Design in HCI Research: The Extended Value Co-creation Model. In Proceedings of the Halfway to the Future Symposium 2019 (HTTF 2019), November 19-20, 2019, Nottingham, United Kingdom. ACM, New York, NY, USA, 8 pages. https://doi.org/10.1145/3363384.3363401

\section{INTRODUCTION}

With the third wave of human-computer interaction (HCI), as defined by Bødker [5], come new research challenges. One of the major trends in the third wave of $\mathrm{HCI}$ is to move away from optimizing efficiency by turning the focus onto experience and meaning-making $[6,24]$. Another major trend is the evolving role of interaction designer from a product designer to a service designer. Forlizzi and Zimmerman argue that product-centric approaches to interaction design are insufficient to appropriately take on complex sociotechnical challenges, and propose service design as a complement [13, 15]. They argue that "a service framing offers a systemic approach that better address the complex stakeholder relationships, yields outcomes in the form of product-service systems, and focuses on how value can be co-produced between customers and stakeholders" [15, p. 1]. Responding to Forlizzi and Zimmerman's call, we ask: What does it mean to engage in service design in an HCI research setting? We explore this question by reflecting on a case study in which we adopted service design models and methods developed in practice settings and tried to apply them in a collaborative research project aimed at developing new digital services for public libraries.

The development of service design has been mainly driven by practitioners. Service design originally emerged from the domains of marketing and management, and over time, developed into a design discipline. Through practice and reflection on what practitioners do, many useful process models and design methods have been developed such as service blueprint [38], customer journey map [40], impact mapping [30], and touchpoints matrix [9] to name a few. However, as Sangiorgi [35] pointed out, service design currently lacks a strong sense of research direction, which is reflected by the limited number of academic publications. According to Roto et al. [33], as of 2017, there were only five CHI papers in the ACM digital library that included "service design" as a keyword.

While practice and research complement each other, we would like to acknowledge a key difference. Design practice focuses on 
producing new artifacts (e.g., devices and services). Design research, in contrast, is primarily concerned with producing new knowledge. In Research through Design (RtD), for example, the knowledge that comes from the process of bringing a new artifact into being or from studying a designed artifact in use is the contribution, while the resulting artifact (e.g., prototype) is considered more as a means than an end $[12,16,46]$. In design practice, outcomes are often evaluated based on economic value, whereas in design research, outcomes are often evaluated based on intellectual merit. In short, design practice and design research are driven by different agendas. The models and methods developed in practice settings sometimes do not work in research settings, and vice versa.

This work contributes to discourses of the designer's roles and positions with a specific focus on value tensions and value co-creation between academic researchers and their partner organizations in a collaborative research project. We do so by providing a model that clarifies the position of design researchers in service design and visualizes how their position impacts the value co-creation process, and in turn, the design outcome. Given a strong commitment for knowledge production and a further commitment for sociotechnical innovation, we argue that HCI design researchers play a distinct role in relation to service design practitioners.

The paper is structured as follows: First, we offer a brief introduction to service design and the concept of value co-creation. Next, we review how designers have been positioned in various $\mathrm{HCI}$ literature. We then introduce the case in question, an international library research project, focusing on key stakeholder values and tensions. We describe the shortcomings of the conventional value co-creation model and service blueprint developed in practice settings and, in turn, suggest an extended value co-creation model adapted to an academic research setting.

\section{BACKGROUND}

\subsection{Value Co-creation in Service Design}

Service design is distinct from product-centric design in that it is systemic [14]. While product-centric design focuses on the design of artifacts, service design turns the focus onto design of interactive systems comprised of multiple resources and stakeholders [19]. In other words, service design extends beyond the traditional productcentric design paradigm by taking into account a complex set of social relations and technological ecologies surrounding the artifact that we build [23]. In particular, Ramirez and Mannervick [31] described service design as the design of "value-creating systems," meaning that to design a service is to organize a system of value creation by redistributing capabilities across a complex network of stakeholders. Such capabilities are "not resources per se, but the ability to access, deploy, exchange, and combine them that lies at the heart of value creation" [26, p. 409].

Traditionally, service providers were primarily charged with responsibility for planning, manufacturing, and delivering services to their customers, who in turn could demand, consume, and evaluate them [29]. Thus, service has been understood as a delivery of value that is predetermined and embedded in the service (see Figure 1). This traditional formulation of service, however, has been critiqued and evolved through the recent development of servicedominant logic [44]. According to service-dominant logic, the value

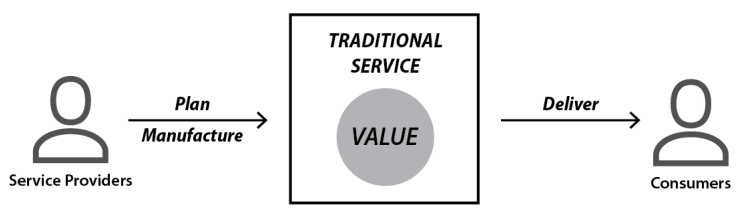

Figure 1: Service as delivery in traditional service design model.

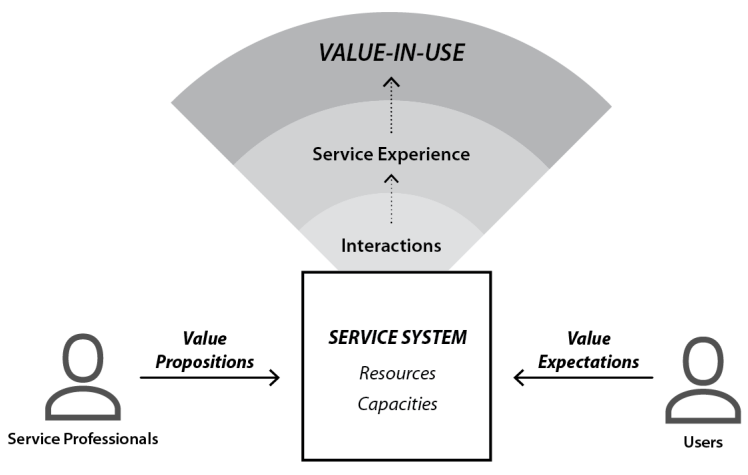

Figure 2: Our interpretation of value co-creation in servicedominant logic.

of a service is co-created in use rather than delivered in exchange. As Meroni and Sangiorgi [25] argue, the key to engage in value co-creation is to understand "the fundamental inability of design to completely plan and regulate services, while instead considering its capacity to potentially create the right conditions for certain forms of interactions and relationships to happen" (p. 10). Service professionals can only propose potential value by creating the right conditions for a positive experience, which users later turn into real value-in-use. Such a process of value co-creation is dialogical (see Figure 2). Users engage in value co-creation by actively interacting with the service and by assessing their subsequent experience of the service. By expressing their expectations and combining resources for their own benefits, the role of users shifts from a mere consumer to a co-creator of value. Service professionals (rather than service providers), in turn, propose potential values based on understanding of what users expect and how users combine resources.

\subsection{Design Researchers as Distinct Stakeholders}

Design is never from nowhere and a designer is never unbiased [39]. Drawing from Haraway's concept of situated knowledge [18], Suchman [42] called for professional designers to take "located accountability" to become responsible for explicitly positioning themselves within the social relations that comprise technical systems. Echoing Suchman's perspective, the HCI community has become 
increasingly aware of the importance of locating and disclosing the designer's own sociocultural position in the world. Reflective design [36] is one compelling example, which argues for a more rigorous, critical approach to reflecting on what values, attitudes, and worldviews designers bring into the design practice. In Participatory Design (PD) literature, Iversen, Halskov, and Leong [21] focused on designers' use of appreciative judgment of values: "the capacity to understand, or appreciate a situation through the discernment of what is to be considered as a background and what is to be considered as foreground in the formation of a project" ( $p$. 92). Iversen and colleagues encouraged designers to be aware of their personal values so as to understand how those values guide their choice of design methods and resources and how it impacts their interpretation of stakeholders' values. Furthermore, in value sensitive design (VSD) literature, Borning and Muller [7] criticized the publication norms in HCI, in which researchers are instructed to anonymize their work and to use a disembodied voice in reporting their investigations. Borning and Muller called for design researchers to disclose their researcher stance and make their voice salient in the writing about their socio-cultural background, their relation to the participants in the study, and their personal values at play that impacted their design judgment.

Building on the above discourses on designer's positions and values, in this paper we will specifically examine the role of design researcher in collaborative research with non-academic partners Borrowing from Nelson and Stolterman [27]'s model of the ideal service design relationship, we visualized service design research partnership as shown in Figure 3. Like Yin and Yang, such a relationship is a dynamically balanced relationship, but it is not a relationship without tensions. As Nelson and Stolterman described: "The model implies that tension lies at the core of the interconnection. It is the complexity of this interconnection, and in the tension between its different qualities, that imaginative and innovative design work takes place" (p. 49). While specific qualities of the stakeholders may differ greatly from case to case, one of the common qualities shared by many design researchers engaging in service design is the intention to drive sociotechnical innovation and to generate new knowledge. Partner organizations, on the other hand, join a research partnership with a desire for service innovation at the very least. Attending to inconsistent conceptions of value and value tensions among diverse partners is one of the most crucial yet challenging tasks in collaborative research [4] especially when the partner organization's understanding of value is skewed towards narrow economic measures [45].

\section{CASE STUDY: DESIGNING DIGITAL SERVICES FOR PUBLIC LIBRARY}

\subsection{Project Synopsis}

In this project, we make use of a computational alternative research agenda [22]. Computational alternatives are not designed to showcase a new technical solution to a well-known problem, but rather to systematically question the technological status quo and peak into a possible future. At the same time, they are not speculative fictions detached from real-world practice. Computational alternatives aim to elucidate sociotechnical issues otherwise taken for

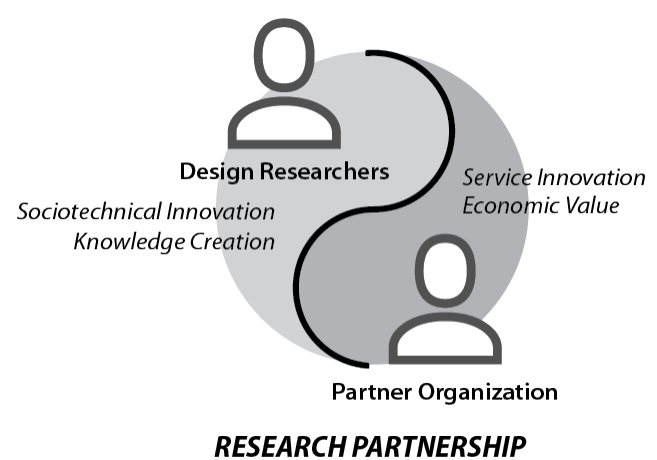

Figure 3: Model of service design research partnership adapted from Nelson and Stolterman [27].

granted, through critical technical development in a concrete use case.

Specifically, we conducted our investigation around the case of exploring computational alternatives for public libraries, namely the PLACED project. Public libraries are undergoing transitions from a quiet study space to a vibrant "third place" $[1,11,28]$. Libraries are taking up a new role to become urban innovation hubs by offering a range of activities that bring together local communities from different neighborhoods and backgrounds. The PLACED project aims to support community events and cultural activities taking place in public libraries by developing digital services to effectively capture knowledge co-created by local residents participating in these events and activities. Furthermore, the project aims to explore how to turn such local knowledge into an integral part of the library collection.

The PLACED project consortium consists of partners from three European countries: Denmark, France, and Sweden. Each country is represented by one research university and one public library. In addition, we have a partner from Sweden that assists in developing a business plan for ensuring the ongoing development and deployment of the digital services when the initial research project funding expires.

\subsection{Method}

We provide a design reflection on value tensions and value cocreation between two key stakeholders of this project: the partner libraries and the design researchers. By partner libraries, we refer to three public libraries participating in this project. By design researchers, we refer to academics who are leading this project, including the authors. First, we will reflect on each stakeholder's values. Next, we identify key tensions that may be of particular interest to the HCI design community.

The stakeholder values have been identified in two ways. First, in order to identify values of the partner libraries, one of the authors conducted a thematic analysis on empirical data collected from co-design sessions and ethnographic investigations from the first year of the project. For collecting data, we used a qualitative multi-site approach [3], where we studied three public libraries, 


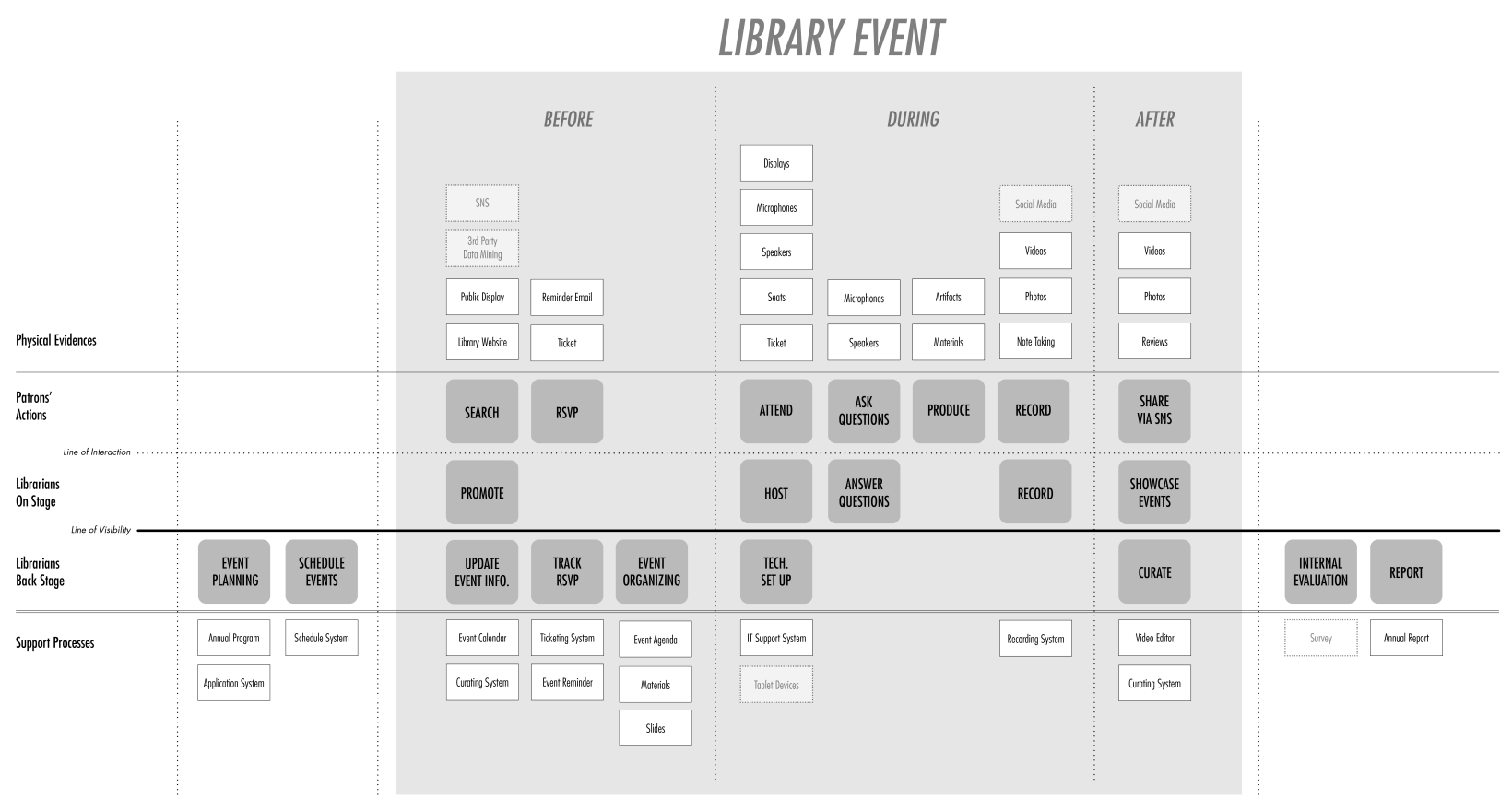

Figure 4: Traditional service blueprint of the PLACED project

each in a different country, over the course of six months. The primary research carried out included (1) ethnographic studies and semi-structured individual and group interviews, (2) co-design workshops with library personnel, and (3) a focus group with library personnel. Secondary research included analysis of the different websites and social media used by the libraries, and the ways in which the libraries market themselves and their activities online. When applicable, statistics were also obtained through the library staff. Next, in order to identify values of the design researchers, another author analyzed the research funding application document using open coding [41] and thematic coding [17]. Among international researchers working across different academic institutions, the research funding application document served as the primary contract and a guide for conducting our design investigations.

\subsection{Identifying Stakeholder Values}

In what follows, we discuss values of the key stakeholders in the project-the partner libraries and the design researchers-in order to surface intersections and tensions, as well as to describe the value co-creation process that we took when these values were brought into play in the project.

3.3.1 Values of the Partner Libraries. As was reported in our previous work [37], the practice of the library staff is guided by value sentiments such as empowerment, freedom of expression, emancipation and democracy, and organized activities at the library are heavily influenced by such ideals. Public libraries have a sense of duty to maintain the status of libraries as free services open for anyone, not seeking to profit upon patrons, and where they can offer spaces for teaching and learning through activities, literature, and by means of the space itself.

Furthermore, the library staff is committed to providing various services to respond to the needs of residents in local areas. For example, the library staff assists patrons in civic matters by helping them to fill out a form or guiding them in printing out necessary documentation. The library space also offers a safe haven for citizens who are in need of a place to stay during the day, such as homeless people. Such efforts, however, often go unnoticed by the public, in part, because of the difficulty measuring the broad impact. Many politicians, who supply the funding, would rather focus on the services that can be measured through statistics such as visitor count, putting a pressure on libraries to stay focused on more popular and highly visible activities.

3.3.2 Values of the Design Researchers. The overarching research goal of the PLACED project is to develop new and dynamic digital services to help public libraries transform from a traditional knowledge institution into a vibrant urban hub. We aim to do so by building a web-based open source infrastructure supporting knowledge creation activities among citizens, and then turning this knowledge into an ever-growing part of the urban community's shared resources. Key design research values include: technological innovation (i.e., leveraging "cutting-edge academic expertise in participatory design, human-computer interaction, activity-based computing and visualization"), localization (i.e., ensuring "a strong rooting in the local challenges' and increasing 'the capacity of urban areas to answer local challenges"), participation (i.e., encouraging "active participation and co-creation of knowledge by citizens to 


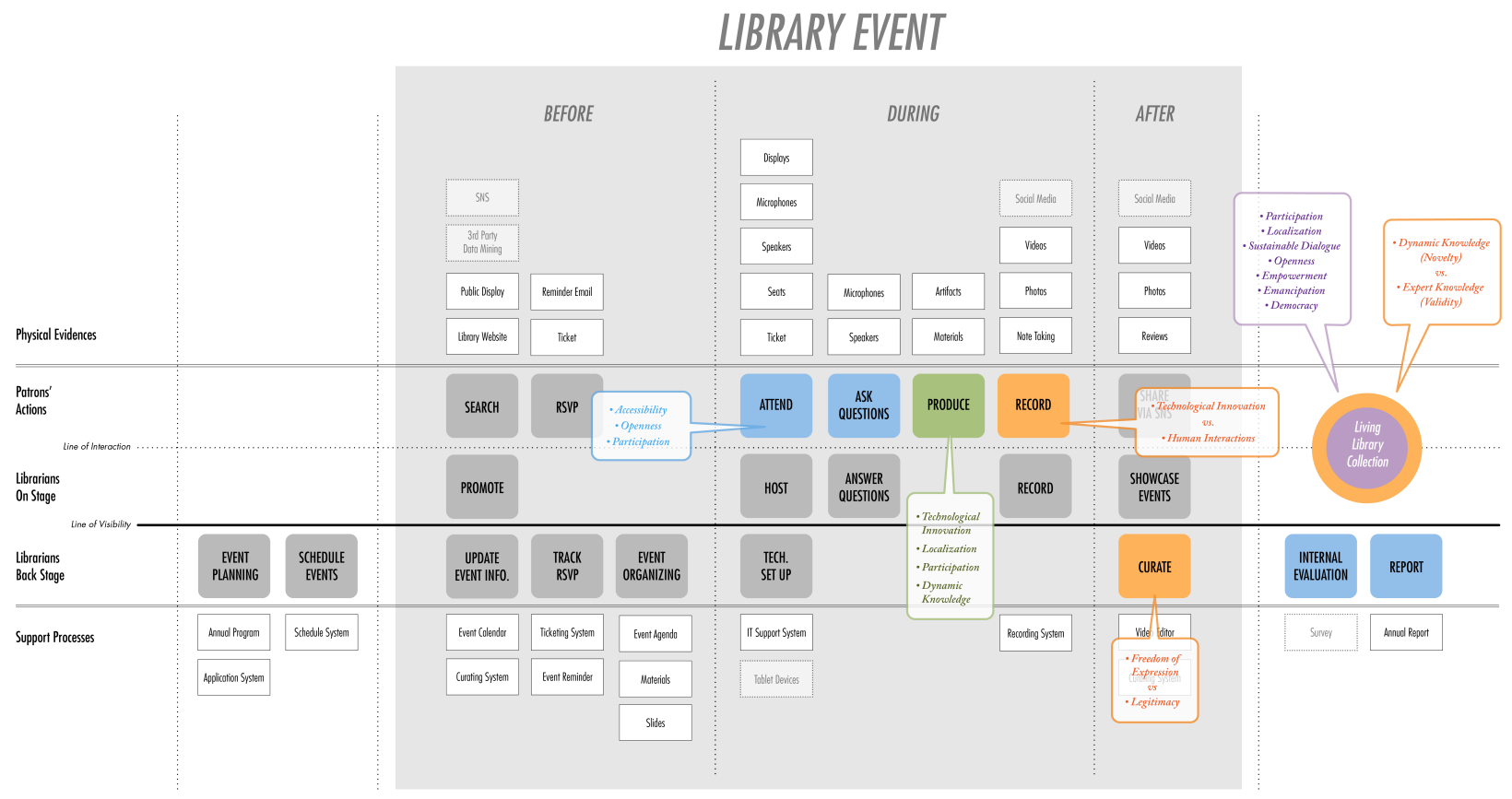

Figure 5: Extended service blueprint of the PLACED project, where (1) blue is where the partner libraries see most values, (2) green is where the design researchers see most values, (3) orange is where we see most tensions, (4) purple is a new service that does not currently exist but for which both the partner libraries and the design researchers see potential values and tensions.

enrich library collections"), dynamic knowledge (i.e., supporting the transformation of public libraries "from static to dynamic urban knowledge hubs," creating a "growing, living library collection fueled by the activities of the citizens who actively use the library"), and sustainable dialogue (i.e., enabling public libraries to "support the evolving needs of urban residents on an ongoing basis through continuous dialogue after the project has ended").

\subsection{Surfacing Value Tensions in the PLACED project}

The partner libraries and the design researchers shared sensibilities around values of participation and sustainable dialogue. The partner libraries, on the one hand, aim to provide a social meeting place, free of charge and open for all, promoting citizen participation. The design researchers, on the other hand, are committed to take a participatory approach in the design process as well as in the use of technology. The partner libraries and the design researchers also shared sensibilities around the desire to meet local needs and engage in local issues. At the same time, there were different, and sometimes diverging, stakeholder values at play in the PLACED project. Here we describe key value tensions arising from: (a) technological innovation versus digital overhead and (b) dynamic knowledge versus traditional knowledge.

3.4.1 Technological Innovation vs. Digital Overhead. Considering value of technological innovation, the partner libraries regarded technology as holding a lot of promise if it supports the underlying values such as accessibility and openness. However, a clear issue in contemporary libraries can be characterized as "digital overhead" that is inevitable for most of the library staff who are not particularly tech savvy. While our partner libraries have indicated that they feel positive towards user-friendly, simple technologies in their everyday work (e.g., their book return robots), they were considerably less pleased when new (and, to them, complicated) digital systems were introduced, as this entails a shift in focus from the social engagement librarians want to take part in, towards occupying a substantial amount of their day dealing with technical issues.

3.4.2 Dynamic Knowledge vs. Traditional Knowledge. The partner libraries viewed knowledge in a traditional sense, where they feature as guardians and providers of the social and cultural heritage of society by means of the expert knowledge that is the library collection. It was clearly important for librarians to maintain, preserve, and safe-guard what should be regarded as library content and what should not. Suggesting an emergent view on dynamic knowledge where anyone and everyone can become a contributor, therefore, might be perceived as a threat toward the legacy of the library and the duty of librarians. Any content that is not produced by the libraries themselves, or supplied through the collection whose legitimacy is ensured, necessitates moderation and curation by the library personnel. This makes the idea of the dynamic knowledge, with which we, the design researchers aim to support a "growing, 
living library collection fueled by the activities of the citizens who actively use the library," inherently problematic.

\subsection{Engaging in Value Co-creation: Extending the Service Blueprint Method}

In the PLACED project, we used service blueprints [38] to communicate stakeholder values and address value tensions. Initially, we generated a traditional version of a service blueprint focusing on interactions and touch points between the library staff and the patrons (see Figure 4). This service blueprint was effective in visualizing the overall work process of organizing a library event and identifying practical needs and pain points of the library staff. However, this service blueprint led us to only focus on well-known problems at hand experienced by the partner libraries within their existing practice (e.g., addressing logistical issues). This service blueprint did not reflect interests of the design researchers who sought to challenge the status quo. Taking the computational alternatives approach, we, the design researchers, were interested in exploring design opportunities that can transform the nature of participation and knowledge co-creation in library events.

Thus, we created an extended version of the service blueprint (see Figure 5). This service blueprint aims to (a) reflect values of the design researchers as well as the partner libraries, (b) surface value tensions, and (c) identify novel opportunities.

\section{THE EXTENDED VALUE CO-CREATION MODEL FOR DESIGN RESEARCH SETTINGS}

With the stakeholder value mapping and identification of tensions in the PLACED project, it became clear that the way design researchers work with their partner organization is different from the way service design practitioners work on behalf of their client organization. Design researchers have a direct stake in the project as they bring in a specific set of research questions, goals, and visions. Different conceptions of value between design researchers and their partner organizations need to be clearly communicated and explicitly negotiated in the design process.

We considered the traditional value co-creation model (see Figure 2) to be insufficient for describing how we worked with our partner organizations. Based on the above insights, we created an extended model of value co-creation (see Figure 6), highlighting the dynamics between design researchers and their partner organizations.

In our new model, design researchers and partner organizations collaboratively define the value proposition for the service system. Partner organizations join the project with desire for service innovation and potential economic value, whereas design researchers join the project with the agenda for sociotechnical innovation and knowledge creation. By recognizing their own values and making them explicit, design researchers become a distinct stakeholder in the value co-creation process. For partner organizations, it is important to understand what the design researcher's values are and how those will impact the value proposition.

We propose that $\mathrm{PD}$ can offer insights into how design researchers can engage with their partner organization in value co-creation. The principle of mutual learning prevalent in PD emphasizes the need for the development of processes and tools that enable more robust communication among those involved in the design process
[32]. Through PD processes, design researchers and partner organizations can learn from each other by understanding each other's practices, values, and priorities. This leads to a more robust value proposition that reflects both the perspectives of design researchers and partner organizations, which leads, in turn, to outcomes that are more likely to be successful.

\subsection{Implications of the Extended Value Co-creation Model for the PLACED project}

There are many implications of the extended value co-creation model in design research. It is beyond the scope of this paper to examine them all, but here we share some of the key implications we encountered in the case of the PLACED project.

First, by reflecting on the traditional service blueprint (see Figure 4) and identifying gaps, we have become aware of the design researchers as a distinct stakeholder. Becoming aware of our own research agenda and values, we have learned to accept them and allowed those values to guide how the project develops. To do so, we have allocated time to explicitly identify and clearly communicate stakeholder values. Specifically, we analyzed key stakeholder values as described in Section 3 and generated an extended version of service blueprint (see Figure 5).

In the process of identifying values, we have also been able to identify tensions. By making the tensions explicit, we were able to explore ways to resolve tensions. Above all, we have learned the importance of trying to communicate an explicit research agenda in every meeting. We have strived to reflect on a shared project vision often, preferably in every contact with the partner organizations. We have organized multiple joint meetings with all the key stakeholders for building common ground and empathy. This is a process that occurs in many projects, but the focus of these meetings was not just about design researchers gaining better understanding of the stakeholders; we have focused on finding ways to make the stakeholders understand us, design researchers, to reach mutual learning. By doing so, the stakeholders can set the right expectations for the project outcomes.

This focus on mutual learning has led us to change our implementation process to that of participatory prototyping, where we as design researchers provide re-configurable alternatives in forms of design prototypes, with which the questions asked are carefully examined and the answers are digested in cooperation with stakeholders [5]. We have further taken on a computational alternative approach, meaning that we now communicate more explicitly to all stakeholders that the main approach in the project is not to solve well-known problems here and now, but rather to systematically question the technological status quo and peak into a possible future [22]. To mitigate the present-future gap that poses challenges to evaluation [34], we have chosen a situated evaluation approach [8].

Furthermore, we aim to incorporate economics as a material for design, to understand the underlying economic model with a wider set of stakeholders [15]. Specifically, we plan to develop a viable business model as a result of the project, which will be reported on elsewhere. 


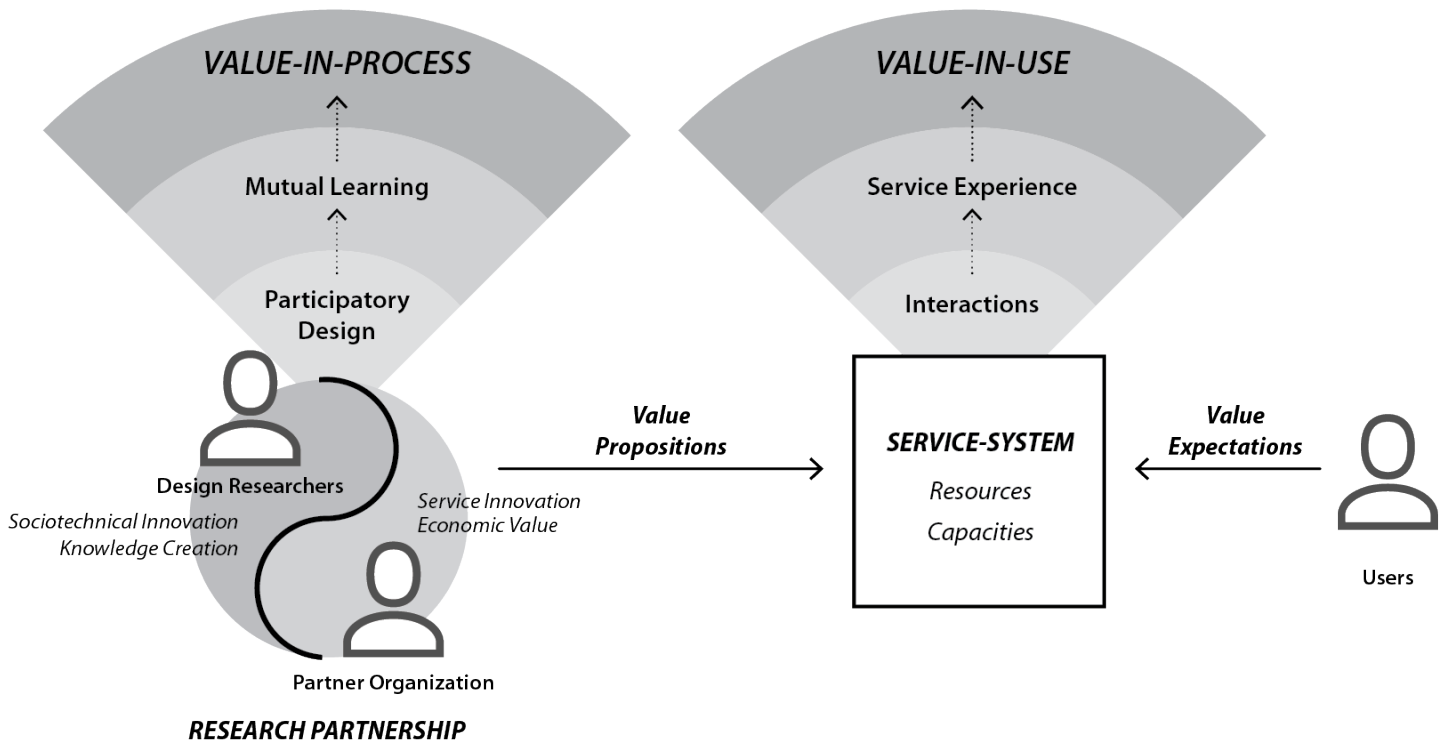

Figure 6: Revised value co-creation model in an academic research setting.

\section{DISCUSSION AND CONCLUSION}

The extended model of value co-creation clarifies the position of design researchers in service design projects, and contributes to broader discourses of the designer's positions and values in HCI. In "When second wave HCI meets third wave challenges", Bødker states: "I am concerned with the possible lack of serious commitment of designers to users [...] As I have pointed out, this leads to a situation where mediators either make us break down or act transparently, but where our ability as human beings to learn and cooperate in communities of practice is largely ignored" [5, p. 6]. We propose that service design, in combination with $\mathrm{PD}$, can serve as a frame for understanding and addressing mutual learning and cooperation in the design of services. Although several researchers have discussed the interplay of research and design as unfolding throughout a design process (e.g., $[2,10]$ ), we have not yet seen this discussion in relation to service design and the HCI researchers as distinct stakeholders who bring their own agenda and values to the project.

We argue that a service design perspective can contribute to design-oriented HCI research since it offers insights on how to address complex sociotechnical systems. However, it also has limitations and embody certain perspectives that must be taken into consideration. Service design originally emerged from the domains of marketing and management, relies on a rather simplistic framing of customer and service provider, and seems timid in its approach to using technology as it often entails the adoption of well-known technology and commercial platforms [46]. In this sense, it embodies some of the traits that Bødker warns against: "The emerging third wave seems strongly tied to a kind of consumerism that differs from the underlying co-determination framework of the Scandinavian societies" [5, p. 6]. One way to address this problem is to adopt an understanding of the notion of value that extends beyond pecuniary aspects and take into consideration a wider understanding of value related to the social and political contexts [45]. PD research such as that of Van der Velden and Mörtberg [43] and Iversen et al. [20] provides useful insights for doing so. In the case of design researchers entering the fray, this expanded understanding of value must also entail the value of sociotechnical innovation and new knowledge created in collaborative partnership between the researchers and the partner organizations.

In this paper, we have discussed how service design can be a complement to HCI research settings, and especially with focus on the role of design researcher. The contribution of this paper is a model of the value co-creation process with design researchers as distinct stakeholders who bring with them their own values and agenda into the project. We have placed our model in the ongoing discourse on how to practice service design in $\mathrm{HCI}$ research and how to address designer values. We hope that readers will borrow and appropriate this model in diverse service design research settings.

\section{ACKNOWLEDGMENTS}

Thanks to all who took part in this study. The work is funded by Vinnova 2017-01553, Innovation Fund Denmark 5123-00007B, Agence Nationale de la Recherche ANR-16-ENSF-0004, and JPI Urban Europe EU 693443. We also thank Erasmus+ 2018-1-SE01KA203-039072. 


\section{REFERENCES}

[1] Svanhild Aabø and Ragnar Audunson. 2012. Use of library space and the library as place. Library \& Information Science Research 34, 2 (2012), 138-149. https //doi.org/10.1016/j.lisr.2011.06.002

[2] Ditte Amund Basballe and Kim Halskov. 2012. Dynamics of Research Through Design. In Proceedings of the Designing Interactive Systems Conference (DIS '12). ACM, New York, NY, USA, 58-67. https://doi.org/10.1145/2317956.2317967

[3] Pam Bishop. 2010. Multi-Site Case Study. In Encyclopedia of Case Study Research A Mills, G Durepos, and E Wiebe (Eds.). SAGE Publications, Inc, Thousand Oaks, CA, USA, 588-591. https://doi.org/10.4135/9781412957397

[4] Michael Mose Biskjaer, Aliakbar Kamari, Stina Rask Jensen, and Poul Henning Kirkegaard. 2019. Exploring blind spots in collaborative value creation in building design: a creativity perspective. CoDesign (2019), 1-18.

[5] Susanne Bødker. 2006. When Second Wave HCI Meets Third Wave Challenges. In Proceedings of the 4th Nordic Conference on Human-computer Interaction: Changing Roles (NordiCHI '06). ACM, New York, NY, USA, 1-8. https://doi.org/10.1145/ 1182475.1182476

[6] Susanne Bødker. 2015. Third-wave HCI, 10 Years Later-participation and Sharing. interactions 22, 5 (Aug. 2015), 24-31. https://doi.org/10.1145/2804405

[7] Alan Borning and Michael Muller. 2012. Next Steps for Value Sensitive Design In Proceedings of the SIGCHI Conference on Human Factors in Computing Systems (CHI '12). ACM, New York, NY, USA, 1125-1134. https://doi.org/10.1145/2207676. 2208560

[8] Bertram Bruce, Andee Rubin, and Junghyun An. 2009. Situated Evaluation of Socio-Technical Systems. https://doi.org/10.4018/9781605669847.ch144

[9] Gianluca Brugnoli. 2009. Connecting the dots of user experience. Fournal of Information Architecture 1, 1 (2009).

[10] Peter Dalsgaard. 2010. Research in and Through Design: An Interaction Design Research Approach. In Proceedings of the 22Nd Conference of the Computer-Human Interaction Special Interest Group of Australia on Computer-Human Interaction (OZCHI '10). ACM, New York, NY, USA, 200-203. https://doi.org/10.1145/1952222. 1952265

[11] J. K. Elmborg. 2011. Libraries as the spaces between us: Recognizing and valuing the third space. Reference \& User Services Quarterly 50, 4 (2011), 338-350.

[12] Daniel Fällman. 2003. Design-oriented Human-computer Interaction. In Proceedings of the SIGCHI Conference on Human Factors in Computing Systems (CHI '03). ACM, New York, NY, USA, 225-232. https://doi.org/10.1145/642611.642652

[13] Jodi Forlizzi. [n. d.]. Moving beyond user-centered design. Interactions 25 ([n d.])

[14] Jodi Forlizzi. 2010. All Look Same?: A Comparison of Experience Design and Service Design. Interactions 17, 5 (Sept. 2010), 60-62. https://doi.org/10.1145/ 1836216.1836232

[15] Jodi Forlizzi and John Zimmerman. 2013. Promoting service design as a core practice in interaction design. In Proceedings of IASDR13. 1-12.

[16] William Gaver. 2012. What Should We Expect from Research Through Design?. In Proceedings of the SIGCHI Conference on Human Factors in Computing Systems (CHI '12). ACM, New York, NY, USA, 937-946. https://doi.org/10.1145/2207676.2208538

[17] Graham R Gibbs. 2007. Analyzing qualitative data. Sage Publications, Inc. Thousand Oaks, CA, US

[18] Donna Haraway. 1998. Situated knowledges: The science question in feminism and the privilege of partial perspective. Feminist studies 14, 3 (1998), 575-599.

[19] Stefan Holmlid. 2007. Interaction Design and Service Design: Expending a Comparison of Design Disciplines. In Proceedings of NORDES'07.

[20] Ole Sejer Iversen, Kim Halskov, and Tuck Leong. 2012. Values-led participatory design. CoDesign 8, 2-3 (2012), 87-103.

[21] Ole Sejer Iversen, Kim Halskov, and Tuck Wah Leong. 2010. Rekindling Values in Participatory Design. In Proceedings of the 11th Biennial Participatory Design Conference (PDC '10). ACM, New York, NY, USA, 91-100. https://doi.org/10. $1145 / 1900441.1900455$

[22] Henrik Korsgaard, Clemens Nylandsted Klokmose, and Susanne Bødker. 2016 Computational Alternatives in Participatory Design: Putting the T Back in Sociotechnical Research. In Proceedings of the 14th Participatory Design Conference: Full Papers - Volume 1 (PDC '16). ACM, New York, NY, USA, 71-79. https: //doi.org/10.1145/2940299.2940314

[23] Ramia Maze and Johan Redström. 2008. Switch! Energy Ecologies in Everyday Life. International fournal of Design. 2, 3 (Nov. 2008). http://www.ijdesign.org/ index.php/IJDesign/article/view/492/222

[24] John McCarthy and Peter Wright. 2004. Technology As Experience. The MIT Press.

[25] Anna Meroni and Daniela Sangiorgi. 2011. Design for services. Grower Publishing.

[26] P. Moran and S. Ghoshal. 1999. Markets, firms, and the process of economic development. Academy of management review 24, 3 (1999), 390-412.

[27] Harold G. Nelson and Erik Stolterman. 2012. The Design Way: Intentional Change in an Unpredictable World. The MIT Press.

[28] R Oldenburg. 1989. The Great Good Place: Cafes, Coffee Shops, Bookstores, Bars, Hairsalons and Other Hangouts at the Heart of Community. Marlowe and Company.
[29] S. P. Osborne, Z. Radnor, and K. Strokosch. 2016. Co-production and the cocreation of value in public services: a suitable case for treatment? Public Management Review 18, 5 (2016), 639-653.

[30] Ingrid Ottersten and Mijo Balic. 2010. Effektstyrning av IT : nyttan uppstår $i$ användningen (2 ed.). Liber, Malmo, Sweden.

[31] Rafael Ramirez and Ulf Mannervik. 2008. Designing Value Creating Systems. In Designing for Services: Multidisciplinary Perspectives - Proceedings from the Exploratory Project on Designing for Services in Science and Technology Based Enterprises, Lucy Kimbell and Victor Seidel (Eds.). Said Business School, University of Oxford, Oxford.

[32] Toni Robertson and Ina Wagner. 2012. Ethics: engagement, representation and politics-in-action. In Routledge International Handbook of Participatory Design. Routledge, Chapter 4. https://doi.org/10.4324/9780203108543.ch4

[33] Virpi Roto, Jung-Joo Lee, Tuuli Mattelmäki, and John Zimmerman. 2018. Experience Design Meets Service Design: Method Clash or Marriage?. In Extended Abstracts of the 2018 CHI Conference on Human Factors in Computing Systems (CHI EA '18). ACM, New York, NY, USA, Article W26, 6 pages. https://doi.org/10.1145/3170427.3170626

[34] Antti Salovaara, Antti Oulasvirta, and Giulio Jacucci. 2017. Evaluation of Prototypes and the Problem of Possible Futures. In Proceedings of the 2017 CHI Conference on Human Factors in Computing Systems (CHI '17). ACM, New York, NY, USA, 2064-2077. https://doi.org/10.1145/3025453.3025658

[35] Daniela Sangiorgi. 2009. Building Up a Framework for Service Design Research. In 8th European Academy Of Design Conference. 415-420.

[36] Phoebe Sengers, Kirsten Boehner, Shay David, and Joseph'Jofish' Kaye. 2005. Reflective design. In Proceedings of the 4th decennial conference on Critical computing: between sense and sensibility. ACM, 49-58.

[37] Sofia Serholt, Eva Eriksson, Peter Dalsgaard, Raphaëlle Bats, and Alix Ducros. 2018. Opportunities and Challenges for Technology Development and Adoption in Public Libraries. In Proceedings of the 10th Nordic Conference on HumanComputer Interaction (NordiCHI '18). ACM, New York, NY, USA, 311-322. https: //doi.org/10.1145/3240167.3240198

[38] Lynn Shostack. 1982. How to Design a Service? European fournal of Marketing 16 (1982), 49-63.

[39] M. L. J. Söndergaard and L. K. Hansen. 2017. Designing with Bias and Privilege. Nordes 20177 (2017)

[40] Marc Stickdorn and Schneider Jakob. 2012. This is Service Design Thinking: Basics, Tools, Cases. Wiley, New York, NY.

[41] Anselm Strauss and Juliet M. Corbin. 1990. Basics of qualitative research: Grounded theory procedures and techniques. Sage Publications, Inc., Thousand Oaks, CA, US.

[42] Lucy Suchman. 2002. Located Accountabilities in Technology Production. Scand. f. Inf. Syst. 14, 2 (Sept. 2002), 91-105. http://dl.acm.org/citation.cfm?id=782686. 782694

[43] M Van der Velden and Christina Mörtberg. 2015. Participatory design and design for values. In Handbook of Ethics, Values, and Technological Design: Sources, Theory, Values and Application Domains. 41-66.

[44] S.L. Vargo and R.F. Lusch. 2004. Evolving to a new dominant logic for marketing. fournal of marketing 68, 1 (2004), 1-17.

[45] Roger Whitham, Simon Moreton, Simon Bowen, Chris Speed, and Abigail Durrant. 2019. Understanding, capturing and assessing value in collaborative design research. CoDesign 1 (2019).

[46] John Zimmerman, Jodi Forlizzi, and Shelley Evenson. 2007. Research Through Design As a Method for Interaction Design Research in HCI. In Proceedings of the SIGCHI Conference on Human Factors in Computing Systems (CHI '07). ACM, New York, NY, USA, 493-502. https://doi.org/10.1145/1240624.1240704 